\title{
UJI AKTIVITAS ANTIOKSIDAN EKSTRAK ETANOL DAUN MURBEI (Morus alba L) ASAL KUPANG, NUSA TENGGARA TIMUR DENGAN METODE DPPH (2,2 DIPHENIL-1- PICRYLHYDRAZYL)
}

\author{
Megawati ${ }^{1}$, Muhammad Aswad $^{2}$,Yohanes D.P. Agung Embu' ${ }^{1}$, Khadijah ${ }^{3}$ \\ ${ }^{1}$ Sekolah Tinggi Ilmu Farmasi Makassar, Daya Kota Makassar \\ 2Fakultas Farmasi Universitas Hasanuddin, Makassar \\ 3Prodi Pendidikan Kimia, Universitas Khairun, Ternate \\ Coresponding Author : megasyahruddin@yahoo.co.id \\ Manuscript recieved:18-01-2019 Revision Accepted: 01-05-2019
}

\begin{abstract}
Abstrak
Murbei (Morus alba L.) merupakan salah satu tanaman yang tumbuh di Indonesia dan banyak digunakan dalam pengobatan tradisional. Beberapa khasiat dari murbei kemungkinan berhubungan dengan daya antioksidannya. Tujuan dari penelitian ini adalah untuk mengetahui aktivitas antioksidan ekstrak etanol daun murbei yang berasal dari Kupang. Daun murbei diekstraksi dengan metode maserasi menggunakan pelarut etanol 70\%. Ekstrak diuji terhadap DPPH sebagai radikal bebas dan diukur pada panjang gelombang $517 \mathrm{~nm}$ dengan menggunakan spektrofotometer UV-Vis. Hasil penelitian menunjukkan ekstrak etanol daun murbei dari Kupang Nusa Tenggara Timur, memiliki aktivitas antioksidan sangat kuat dengan nilai IC50 $8,35 \mu \mathrm{g} / \mathrm{mL}$, namun masih lebih rendah dibandingkan kuersetin sebagai kontrol positif dengan nilai IC50 0,82 $\mu \mathrm{g} / \mathrm{mL}$. Penelitian ini menyimpulkan bahwa ekstrak etanol daun murbei dari Kupang memiliki aktivitas antioksidan yang sangat kuat.
\end{abstract}

Kata Kunci: Antioksidan, murbei (Morus alba L.), DPPH (2,2-diphenyl- 1picrylhydrazyl)

\begin{abstract}
Mulberry (Morus alba L.) is one of the plants growing in Indonesia and widely used as traditional medicine. Some efficacy of mulberry might be related to its antioxidant activity. The aim of this study was to determine the antioxidant potency of ethanol extract of mulberry leaves from Kupang. Mulberry leaves was extracted by maceration method using ethanol 70\% as solvent. The extract was evaluated against DPPH as free radical and measured at $517 \mathrm{~nm}$ wavelength using UV-Vis spectrophotometer. The results showed that ethanol extract of mulberry leaves from Kupang Nusa Tenggara Timur, had a very strong antioxidant activity with IC50 value was $8,35 \mu \mathrm{g} / \mathrm{mL}$, However it still lower than quercetin as positive control with IC50 value about $0,82 \mu \mathrm{g} / \mathrm{mL}$. The study can be concluded that ethanol extract of mulberry leaves from Kupang had a very strong antioxidant activity.
\end{abstract}

Keywords: Antioxidant, mulberry (Morus alba L.), DPPH (2,2-diphenyl-1picrylhydrazyl) 


\section{PENDAHULUAN}

Pemanfaatan tumbuhan sebagai obat sudah dilakukan sejak dahulu. Tumbuhan memiliki sejuta manfaat, salah satunya adalah sebagai obat untuk berbagai penyakit (Prasetyono,2012).

Murbei merupakan salah satu tanaman yang tumbuh di Indonesia dan banyak digunakan dalam pengobatan secara tradisional. Daun murbei digunakan dalam masyarakat untuk mengobati berbagai penyakit seperti demam, batuk, sakit kepala, darah tinggi, kencing manis, kaki gajah, sakit kulit, dan gangguan pencernaan (Djamil dan Fatimah, 2015). Kandungan senyawa aktif yang terdapat pada daun murbei yaitu alkaloid, flavonoid, polifenol dan terpenoid yang mempunyai peranan sebagai antioksidan (Jurian,dkk., 2016).

Aktivitas antioksidan dapat ditentukan dengan beberapa metode. Salah satunya adalah metode peredaman radikal bebas DPPH. Pengujian akivitas antioksidan ekstrak daun murbei pernah dilakukan dengan metode DPPH yang sampelnya diambil dari Agrotechnopark Universitas Jember dengan persen penghambatan tertinggi terhadap DPPH sebesar 43,95\% (Jurian, dkk., 2016). Namun, pengujian antioksidan murbei dari daerah Nusa Tenggara Timur khususnya Kota Kupang yang juga banyak ditumbuhi murbei belum pernah dilakukan. Hal ini disebabkan pemanfaatan murbei sebagai pengobatan sendiri masih belum banyak diketahui oleh masyarakat disana pada umumnya.

Menurut Ghasemi et al., (2011), perbedaan kondisi geografis dan keadaan iklim dapat menyebabkan perbedaan komponen bioaktif dan bioaktivitas suatu tanaman. Penelitian yang dilakukannya membuktikan bahwa ekstak metanol Jugians regia L. yang berasal dari 11 wilayah di Iran memiliki aktivitas antioksidan yang berbeda. Dari semua sampel yang diuji, sampel dari daerah Chogholondi memiliki aktivitas penghambatan radikal bebas yang paling kuat dengann IC50 $122 \mu \mathrm{g} / \mathrm{mL}$, sedangkan sampel yang berasal dari daerah Imam Reza Park menunjukan aktivitas penghambatan paling lemah dengan IC50 $302 \mu \mathrm{g} / \mathrm{mL}$. Berdasarkan uraian ini maka peneliti tertarik untuk melakukan penelitian mengenai uji aktivitas antioksidan daun murbei yang berasal dari Kota Kupang, Nusa Tenggara Timur dengan menggunakan metode DPPH.

\section{METODE PENELITIAN}

\section{Cara Kerja}

\section{Penyiapan Sampel}

Sampel daun murbei dikumpulkan, lalu disortasi basah dengan tujuan untuk memisahkan kotoran atau bahan asing lainnya dengan cara dibersihkan dengan menggunakan air mengalir selanjutnya dirajang, dikeringkan, kemudian disortasi kering setelah itu diserbukkan dan siap diekstraksi.

\section{Ekstraksi Sampel Secara Maserasi}

Sebanyak 300 gram simplisia daun murbei dimaserasi menggunakan pelarut etanol $70 \%$ selama $3 \times 24$ jam diaduk sesekali kemudian disaring lalu dilakukan remaserasi lagi selama $2 \times 24$ jam. Ekstrak cair yang telah diperoleh dikumpulkan dan diuapkan pelarutnya dengan alat rotary evaporator hingga diperoleh ekstrak kental daun murbei. 
Selanjutnya dilakukan uji kualitatif ekstrak.

\section{Uji Aktivitas Antioksidan}

a. Pembuatan Larutan DPPH Larutan DPPH 0,4 $\mathrm{mM}$ dibuat dengan cara menimbang DPPH sebanyak 0,0157 g dilarutkan dengan $100 \mathrm{~mL}$ etanol absolut dalam labu ukur.

b. Pembuatan Larutan Sampel

Dibuat larutan stok $1000 \mu \mathrm{g} / \mathrm{mL}$ dengan cara menimbang ekstrak daun murbei 10 mg dan dilarutkan dengan etanol absolut sambil diaduk dan dihomogenkan lalu dicukupkan volumenya hingga $10 \mathrm{~mL}$.

c. Pembuatan Larutan Pembanding Kuersetin

Dibuat larutan stok $1000 \mu \mathrm{g} / \mathrm{mL}$ disiapkan dengan cara menimbang $10 \mathrm{mg}$ Kuarsetin dan dilarutkan dengan etanol absolut, volume akhir dicukupkan hingga 10 $\mathrm{mL}$.

\section{Pengukuran Aktivitas Antioksidan}

a. Pengukuran Antioksidan Blanko

Pengujian dilakukan dengan cara memipet $1 \mathrm{~mL}$ DPPH 0,4 mM dan dicukupkan volumenya dengan etanol absolut hingga $5 \mathrm{~mL}$, larutan dihomogenkan dan didiamkan selama 30 menit, selanjutnya diukur dengan spektrofotometer UV-Vis pada panjang gelombang $517 \mathrm{~nm}$.

b. Pengukuran Antioksidan Ekstrak Etanol daun Murbei.

Pengujian dilakukan dengan cara membuat 5 seri konsentrasi ekstrak, masingmasing dipipet $10 \mu \mathrm{l}, 20 \mu \mathrm{l}, 30 \mu \mathrm{l}, 40 \mu \mathrm{l}$, dan $50 \mu \mathrm{l}$ dari larutan stok sampel ekstrak daun murbei $1000 \mu \mathrm{g} / \mathrm{mL}$ kemudian ditambahkan $1 \mathrm{~mL}$ DPPH lalu dicukupkan volumenya $5 \mathrm{~mL}$ dengan etanol absolut sehingga diperoleh larutan dengan konsentrasi $2 \mu \mathrm{g} / \mathrm{mL}, 4 \mu \mathrm{g} / \mathrm{mL}, 6 \mu \mathrm{g} / \mathrm{mL}, 8 \mu \mathrm{g} / \mathrm{mL}$, dan $10 \mu \mathrm{g} / \mathrm{mL}$. Selanjutnya dihomogenkan dan didiamkan selama 30 menit kemudian diukur dengan spektrofotometer UV-Vis pada panjang gelombang $517 \mathrm{~nm}$.

c. Pengukuran Antioksidan Dengan Larutan Pembanding Kuersetin.

Larutan stok kuersetin $1000 \mu \mathrm{g} / \mathrm{mL}$ dipipet $100 \mu$ d dilarutkan dalam $10 \mathrm{ml}$ etanol absolut sehingga diperoleh larutan stok $10 \mu \mathrm{g} / \mathrm{mL}$. Pengujian dilakukan dengan cara membuat 5 seri konsentrasi larutan pembanding kuarsetin, masing-masing dipipet $100 \mu \mathrm{l}, 200 \mu \mathrm{l}, 300 \mu \mathrm{l}, 400 \mu \mathrm{l}$, dan $500 \mu \mathrm{l}$ dari larutan stok kuarsetin 10 $\mu \mathrm{g} / \mathrm{mL}$, campuran ditambah $1 \mathrm{~mL}$ larutan $\mathrm{DPPH}$ lalu dicukupkan volumenya sampai $5 \mathrm{~mL}$ dengan etanol absolut sehingga diperoleh larutan 0,2 $\mu \mathrm{g} / \mathrm{mL}, 0,4$ $\mu \mathrm{g} / \mathrm{mL}, 0,6 \mu \mathrm{g} / \mathrm{mL}, 0,8 \mu \mathrm{g} / \mathrm{mL}$, dan $1 \mu \mathrm{g} / \mathrm{mL}$. Selanjutnya dihomogenkan dan didiamkan selama 30 menit kemudian diukur dengan spektrofotometer UV-Vis pada panjang gelombang $517 \mathrm{~nm}$.

\section{HASIL DAN PEMBAHASAN}

Sampel yang digunakan pada penelitian ini adalah daun murbei (Morus alba L.) yang berasal dari Kupang-NTT yang diekstraksi dengan menggunakan metode maserasi. Metode penyarian yang digunakan adalah metode maserasi sederhana. Metode 
maserasi merupakan cara ekstraksi yang mudah dilakukan dan dalam tahapannya tidak dilakukan proses pemanasan sehingga menghindari kerusakan zat aktif yang dikandung oleh simplisia (Agoes, 2007). Metode ini cocok untuk mengekstraksi sampel yang mengandung senyawa yang bersifat termolabil (Pandey dan Shalini, 2014). Pada metode maserasi, sampel yang telah dikeringkan terlebih dahulu dirajang kecil dengan tujuan untuk memperbesar luas permukaan sampel. Sampel daun murbei yang telah dirajang kecil ditimbang sebanyak $300 \mathrm{~g}$ kemudian direndam dalam bejana maserasi dengan cairan penyari etanol 70\% selama 3 hari. Etanol 70\% digunakan sebagai penyari karena memiliki kemampuan menyari senyawa pada rentang polaritas yang luas mulai dari senyawa polar hingga non polar (Padmasari et al, 2013). Sehingga diharapkan senyawa-senyawa yang berpotensi sebagai antioksidan dapat tersari secara maksimal. Cairan penyari akan menembus dinding sel sampel dan masuk ke dalam rongga sel yang mengandung zat aktif, zat aktif akan larut dalam cairan penyari sehingga terjadi perbedaan konsentrasi antara larutan zat aktif di dalam sel dan diluar sel, dan proses ini terjadi berulang kali sampai terjadi keseimbangan antara konsentrasi cairan zat aktif di dalam sel dan di luar sel (Ansel, 1989). Untuk mengoptimalkan proses ini, maka ekstraksi dilakukan sebanyak 2 kali (remaserasi). Ekstrak cair kemudian diuapkan sehingga diperoleh ekstrak kental sebanyak 34,663 g dengan rendemen 11,553\%.

Tabel 1. Hasil Perhitungan Rendemen Ekstrak Daun Murbei

\begin{tabular}{lccc}
\hline Sampel & $\begin{array}{c}\text { Simplisia } \\
(\mathrm{g})\end{array}$ & Bobot Ekstrak (g) & Rendemen(\%) \\
\hline $\begin{array}{l}\text { Ekstrak Etanol Daun Murbei } \\
\text { (Morus alba L.) }\end{array}$ & 300 & 34,663 & $11,55 \%$ \\
\hline
\end{tabular}

Setelah ekstrak diperoleh kemudian dilakukan identifikasi kandungan kimia. Hasil identifikasi kandungan kimia dari ekstrak etanol daun murbei dapat dilihat pada tabel berikut:

Tabel 2. Hasil Identifikasi Kandungan Kimia

\begin{tabular}{|c|c|c|c|c|}
\hline No & Senyawa & Pereaksi & Hasil & Keterangan \\
\hline \multirow{3}{*}{1} & \multirow{3}{*}{ Alkaloid } & Mayer & Terbentuk endapan & Positif \\
\hline & & Wagner & $\begin{array}{l}\text { Terbentuk warna } \\
\text { coklat }\end{array}$ & Positif \\
\hline & & Dragendorf & $\begin{array}{l}\text { Terbentuk warna } \\
\text { orange }\end{array}$ & Positif \\
\hline 2 & Flavanoid & $\begin{array}{l}\text { Serbuk } \mathrm{Mg}+\mathrm{HCl} \\
\text { pekat }\end{array}$ & Terbentuk warna & Positif \\
\hline 3 & Saponin & $\begin{array}{l}\text { Aquadest panas } \\
+\mathrm{HCl} 2 \mathrm{~N}\end{array}$ & $\begin{array}{l}\text { Terbentuk busa } \\
\text { yang stabil selama } 10\end{array}$ & Positif \\
\hline 4 & Tanin & $\mathrm{FeCl}_{3}$ & $\begin{array}{l}\text { Terbentuk warna } \\
\text { hijau }\end{array}$ & Positif \\
\hline 5 & Terpenoid & $\begin{array}{l}\text { Kloroform }+ \text { asam } \\
\text { sulfat pekat }+2 \mathrm{~mL} \\
\text { asam asetat anhidrat. }\end{array}$ & $\begin{array}{l}\text { Terbentuk warna } \\
\text { merah tua }\end{array}$ & Positif \\
\hline
\end{tabular}




\begin{tabular}{llll}
\hline Steroid & $\begin{array}{l}\text { Kloroform }+ \text { asam } \\
\text { sulfat pekat }+2 \mathrm{~mL} \\
\text { asam asetat anhidrat. }\end{array}$ & $\begin{array}{l}\text { Lapisan coklat yang } \\
\text { terbentuk pada } \\
\text { pertemuan dua lapisan }\end{array}$ & Positif \\
\hline
\end{tabular}

Hasil skrining fitokimia (Tabel 2) menunjukkan bahwa senyawa yang terkandung dalam ekstrak etanol daun murbei adalah alkaloid, flavonoid, tanin, saponin, steroid, dan terpenoid. Pengukuran daya antioksidan terhadap ekstrak etanol daun murbei dilakukan dengan metode DPPH. Metode DPPH dipilih karena memerlukan sedikit sampel, sederhana, mudah, cepat, dan peka untuk mengevaluasi aktivitas antioksidan dari senyawa bahan alam (Hanani, dkk.2005). Secara kimia senyawa antioksidan adalah senyawa pemberi elektron (elektron donor). Antioksidan bekerja dengan cara mendonorkan satu elektronnya kepada senyawa yang bersifat oksidan sehingga aktivitas senyawa oksidan tersebut dapat dihambat (Winarti,2010). Senyawa antioksidan yang bereaksi dengan radikal DPPH menyebabkan absorbsi DPPH akan berkurang yang ditandai dengan adanya perubahan warna radikal bebas DPPH yang berwarna ungu menjadi kuning pucat (Haeria, dkk., 2016).). Panjang gelombang maksimum DPPH yang didapat untuk pengukuran aktivitas antioksidan ekstrak etanol daun murbei adalah $517 \mathrm{~nm}$. Parameter yang digunakan untuk menunjukan aktivitas antioksidan adalah Inhibition concentration (IC50). Nilai IC50 adalah nilai yang menunjukan konsentrasi antioksidan yang mampu menghambat $50 \%$ oksidasi atau aktivitas radikal bebas (Haeria, dkk., 2016).

Kategori penentuan kekuatan aktivitas antioksidan menurut Molyneux (2004) menyatakan suatu senyawa memiliki antioksidan sangat kuat apabila nilai IC50 < 50 ppm, kuat apabila 50-100 ppm, sedang apabila 101- 150 ppm dan lemah apabila nilai IC50 > 150 ppm.

Tabel 3 dan 4 menunjukkan hasil pengukuran aktivitas antioksidan ekstrak etanol daun murbei (Morus alba $L$ ) dari Kota Kupang dan kuarsetin sebagai pembanding dengan metode DPPH.

Tabel 3. Hasil perhitungan pengukuran aktivitas antioksidan ekstrak etanol daun murbei (Morus alba L) asal Kupang-NTT

\begin{tabular}{|c|c|c|c|c|c|}
\hline $\begin{array}{l}\text { Konsentrasi } \\
(\mathrm{ppm})\end{array}$ & $\begin{array}{c}\text { Absorbansi } \\
(\mathrm{nm})\end{array}$ & Rata-rata & $\begin{array}{c}\% \text { peredaman } \\
\text { DPPH }\end{array}$ & Persamaan garis & $\begin{array}{c}\text { Nilai IC50 } \\
(\mu \mathrm{g} / \mathrm{mL})\end{array}$ \\
\hline & 0,50409 & & & & \\
\hline \multirow[t]{3}{*}{2} & 0,50370 & 0,50407 & 19,92 & & \\
\hline & 0,50444 & & & & \\
\hline & 0,45021 & & & & \\
\hline \multirow[t]{3}{*}{4} & 0,45132 & 0,44965 & 28,56 & & \\
\hline & 0,44744 & & & $Y=4,8335 x+$ & 8,35 \\
\hline & 0,39272 & & & 9,621 & \\
\hline \multirow[t]{3}{*}{6} & 0,38771 & 0,39001 & 38,04 & & \\
\hline & 0,38961 & & & $R^{2}=0,9987$ & \\
\hline & 0,32758 & & & & \\
\hline \multirow[t]{3}{*}{8} & 0,32256 & 0,32662 & 48,11 & & \\
\hline & 0,32973 & & & & \\
\hline & 0,26347 & & & & \\
\hline
\end{tabular}


TECHNO: Vol. 08 ( 01) Mei 2019

\begin{tabular}{llll}
\hline 10 & 0,25490 & 0,26129 & 58,48 \\
& 0,26550 & & \\
Blanko & 0,62990 & & \\
& 0,62965 & 0,62946 & \\
& 0,62883 & & \\
\hline
\end{tabular}

Tabel 4. Hasil perhitungan pengukuran aktivitas antioksidan kuersetin

\begin{tabular}{|c|c|c|c|c|c|}
\hline $\begin{array}{l}\text { Konsentrasi } \\
\text { (ppm) }\end{array}$ & $\begin{array}{l}\text { Absorbansi } \\
(\mathrm{nm})\end{array}$ & Rata-rata & $\begin{array}{c}\text { \% peredaman } \\
\text { DPPH }\end{array}$ & Persamaan garis & $\begin{array}{l}\text { Nilai IC50 } \\
(\mu \mathrm{g} / \mathrm{mL})\end{array}$ \\
\hline & 0,51823 & & & & \\
\hline \multirow[t]{3}{*}{0,2} & 0,5213 & 0,52024 & 27,21 & & \\
\hline & 0,52119 & & & & \\
\hline & 0,47448 & & & & \\
\hline \multirow{5}{*}{0,4} & 0,47415 & 0,47462 & 33,59 & & \\
\hline & 0,47524 & & & $Y=$ & 0,82 \\
\hline & 0,42085 & & & $38,055 x+18,845$ & \\
\hline & 0,42027 & 0,42078 & 41,13 & & \\
\hline & 0,42122 & & & & \\
\hline \multicolumn{6}{|l|}{0,6} \\
\hline & 0,36569 & & & & \\
\hline \multirow[t]{3}{*}{0,8} & 0,36659 & 0,36589 & 48,80 & & \\
\hline & 0,36539 & & & & \\
\hline & 0,30547 & & & & \\
\hline \multirow[t]{3}{*}{1,0} & 0,30782 & 0,30256 & 57,66 & & \\
\hline & 0,29439 & & & & \\
\hline & 0,71443 & & & & \\
\hline \multirow{2}{*}{ Blanko } & 0,71504 & 0,71473 & & $R^{2}=0,9967$ & \\
\hline & 0,71472 & & & & \\
\hline
\end{tabular}

Pada pengujian aktivitas antioksidan menggunakan metode DPPH menunjukkan bahwa ekstrak etanol daun murbei (Morus alba L) dari Kota Kupang mempunyai aktivitas antioksidan dengan nilai IC50 8,35 $\mu \mathrm{g} / \mathrm{mL}$ dan kuersetin sebagai pembanding positif yang merupakan senyawa murni mempunyai aktivitas antioksidan dengan nilai IC50 $0,82 \mu \mathrm{g} / \mathrm{mL}$. Hal ini menunjukan bahwa ekstrak etanol daun murbei (Morus alba L) dari Kota Kupang dan senyawa pembanding kuarsetin memiliki aktivitas antioksidan yang sangat kuat karena memiliki nilai IC50 $<50 \mu \mathrm{g} / \mathrm{mL}$. Pengujian akivitas antioksidan daun murbei pernah dilakukan oleh Muslim (2017). Dengan metode ABTS dan FRAP yang sampelnya diambil dari Kabupaten Gowa, Sulawesi Selatan dengan nilai IC50 sebesar 13,146 $\mu \mathrm{g} / \mathrm{mL}$ dan merupakan antioksidan yang sangat kuat. Pengujian Aktivitas Antioksidan Ekstrak Etanol Daun Murbei juga pernah dilakukan dengan metode DPPH yang sampelnya diambil dari Agrotechnopark Universitas Jember yang memiliki persen penghambatan tertinggi terhadap DPPH sebesar 43,95\% (Jurian, dkk., 2016). Hal ini menunjukan adanya perbedaan potensi aktivitas antioksidan daun murbei dari beberapa daerah yang berbeda. 
Megawati, Aswad, M., Embu, Y.D.P.A, Khadijah. Antioksidan, murbei (Morus alba L.), DPPH (2,2-diphenyl- 1-picrylhydrazyl)

\section{PENUTUP}

Berdasarkan hasil penelitian yang telah dilakukan dapat disimpulkan bahwa ekstrak etanol daun murbei asal kota Kupang NTT yang diuji aktivitas antioksidannya dengan metode DPPH memiliki aktivitas antioksidan yang sangat kuat dengan nilai IC50 8,35 $\mu \mathrm{g} / \mathrm{mL}$.

\section{SARAN}

Perlu dilakukan pengujian kadar fenolik total daun murbei dan dilakukan isolasi lebih lanjut untuk mendapatkan senyawa murni dari daun murbei yang berasal dari Kota Kupang Nusa Tenggara Timur.

\section{DAFTAR PUSTAKA}

Agoes, G. (2007) Teknologi Bahan Alam, ITB Press: Bandung

Ansel, H.C., (1989). Pengantar Bentuk Sediaan Farmasi, diterjemahkan oleh Farida Ibrahim, UI Press, Jakarta

Djamil, R., dan Fatimah Bakriyyah. (2015). Isolasi dan Identifikasi Jenis Senyawa Flavonoid dalam Fase n-Butanol Daun Murbei (Morus alba L.) secara Spketrofotometri, Jurnal Ilmu Kefarmasian Indonesia, 13 (2): 195.

Ghasemi, K., Yousef Ghasemi., Abdollah,E.,Sey ed, M.N.,Seyed, F.N., Mohammad, A. E., Fereshteh, P.,et al, (2011) Influence of Environmental Factors on Antioxidant Activity, Phenol and Flavonoids Contents of Walnut (Juglans regia L.) green husks, Journal of Medicinal Plants Research, 5 (7): 1130.

Haeria, H., dan Andi, T. U. (2016) Penentuan Kadar Flavonoid Total dan Aktivitas Antioksidan Ekstrak Etanol Daun Bidara (Ziziphus spina- christi L.), Journal of Pharmaceutical and Medicinal Science (1): pp 57-61

Hanani, E., Mun'im, A. dan Sekarini, R. (2005) Identifikasi Senyawa Antioksidan dalam Spons Callyspongia Sp. dari Kepulauan Seribu, Majalah Ilmu Kefarmasian, 2 (3): 127.

Jurian, Y. V., Soni Sumasono., dan Mukhammad Fauzi. (2016) Aktivitas Antioksidan dan Antibakteri Ekstrak Daun Murbei (Morus alba) Terhadap Escherichia coli, Universitas Jember, Jember.

Molyneux, P. (2004) Use of The Stable Free Radical Diphenylpicrylhydrazil (DPPH) for Estimating Antioxidant Activity, Journal of Science and Technologi, 26(2): 211219.

Muslim, R. (2017). Uji Aktivitas Antioksidan Ekstrak Etanol Daun Murbei (Morus alba L.) Dengan Metode ABTS (Asam 2,2-Azinobis(3-etilbenzatizolin)-6-sulfonat Dan Metode FRAP (Ferric Reducing Antioxidant Power). [Skripsi]. Sekolah Tinggi Ilmu Farmasi Makassar: Makassar.

Padmasari, P.D., Astuti, K.W., dan Wardiatini, N.K. (2013) Skrining Fitokimia Ekstrak Etanol 70\% Rimpang Bangle (Zingiber purpureum Roxb.), Fakultas Matematika dan Ilmu Pengetahuan Alam, Universitas Udayana Bali. 
Pandey, Amita dan Shalini Tripathi. (2014) Concept of Standadardization, Extraction and Pre Phytochemical Screening Strategies for Herbal Drug, Institute of Technology and Management Sitapur, Journal of Pharmacognosy and Phytochemistry.

Prasetyono, D. S. (2012) A-Z Daftar Tanaman Obat Ampuh Di Sekitar Kita, FlashBooks, Yogyakarta.

Winarti, S. (2010) Makanan Fungsional: Yogyakarta 